\title{
Influence of the hydrophobic interface and transition metal ions on the conformation of amyloidogenic model peptides
}

\author{
M. Hoernke a, B. Koksch b , G. Brezesinski ${ }^{\text {a,* }}$ \\ a Max-Planck-Institute of Colloids and Interfaces, Department of Interfaces, Am Muehlenberg 1a, 14476 Potsdam, Germany \\ ${ }^{\mathrm{b}}$ Free University of Berlin, Institute of Organic Chemistry, Takustr 3, 14195 Berlin, Germany
}

\section{A R T I C L E I N F O}

\section{Article history:}

Received 16 December 2009

Received in revised form 18 February 2010

Accepted 20 February 2010

Available online 1 March 2010

\section{Keywords:}

Amyloid formation

Model peptide

Metal ion complexation

Hydrophobic interface

\begin{abstract}
A B S T R A C T
The transition of $\alpha$-helical or unfolded peptides and proteins to $\beta$-sheets and the subsequent amyloid formation are characteristic for neurodegenerative diseases like Alzheimer's or Parkinson's disease. The interactions of amyloidogenic peptides with surfaces such as biological membranes are considered to play an important role regarding the onset of secondary structure changes. In our project, we used a peptide designed to have specific secondary structure propensities in order to investigate the driving forces and conditions which lead to the $\beta$-sheet formation. The model peptide is able to adopt the coiled coil conformation, $\alpha$-helical peptide strands that wind around each other in a superhelical structure. In addition to building principles stabilizing this $\alpha$-helical conformation it also has $\beta$-sheet stabilizing features. We focused on the interactions of the peptide with the hydrophobic air-water interface. Infrared reflection absorption spectroscopy was used as a surface sensitive method and complemented with grazing incidence $\mathrm{X}$-ray diffraction and reflectivity. Furthermore, the model peptide provides metal binding sites. The binding of transition metal ions leads to a local preference of certain secondary structure elements, depending on the metal ion and the geometry of metal ion binding sites. The interplay and competition of the two trigger mechanisms (1) interaction with surfaces and (2) metal ion complexation were investigated. We found that the secondary structure of the peptide strongly depends on the interactions with the hydrophobic air-water interface and the orientation imposed by it. The metal ions $\mathrm{Zn}^{2+}$ and $\mathrm{Cu}^{2+}$ were used for complexation. The structure of the peptide surface layer differs according to the bound metal ion.
\end{abstract}

(c) 2010 Elsevier B.V. All rights reserved.

\section{Introduction}

Neurodegenerative diseases like Alzheimer's or Parkinson's disease are connected to a misfolding of amyloidogenic peptides. Recently, the early stages of amyloid formation, protofibrils and oligomers are discussed as crucial steps in neurotoxicity. Soluble oligomers and protofibrils have been found to be toxic to neuronal cells [1-3]. Links between soluble oligomers and pathology are discussed for neurodegenerative diseases [4-6].

The mechanism of the very beginning of amyloid formation is still unclear. Most amyloidogenic peptides occur physiologically in an unstructured conformation before transformation to $\beta$-sheet structures and fibrils.

A possible trigger for the misfolding is the interaction of the peptides with interfaces like membranes [7,8] or damaged biomembranes $[9,10]$. Therefore, interactions with different interfaces have been investigated for all kinds of amyloidogenic peptides (for example [11-17]). The interactions with hydrophobic surfaces or

\footnotetext{
* Corresponding author. Tel.: +49 331567 9234; fax: +49 3315679202.

E-mail addresses: hoernke@mpikg.mpg.de (M. Hoernke),

koksch@chemie.fu-berlin.de (B. Koksch), brezesinski@mpikg.mpg.de (G. Brezesinski).
}

charged membrane models are widely accepted, while generally less or no interaction with hydrophilic and uncharged surfaces was found (for example [18] and [19]).

For the Alzheimer related peptide $A_{\beta}$ bound to membrane models, electrostatic and hydrophobic interactions were distinguished by Bokvist et al. [14], while Murphy [8] focused on kinetic effects of membrane interaction.

Usually a lag time before the onset of aggregation is observed in bulk systems, but it is markedly decreased or omitted at the interface. $[9,17,18]$ For $A_{\beta}$, the lag time before $\beta$-sheet formation is drastically shortened upon interaction with membrane models, so that membrane mimicking conditions are used to study an analogous, but slowed down process $[12,20]$.

The role of $\alpha$-helical intermediates in the first steps of the amyloid folding pathway of $A_{\beta}$ and other amyloidogenic peptides is under debate [21-23]. Various studies dealt with $\alpha$-helical intermediates, especially in combination with membrane binding, e.g. for islet amyloid polypeptide [16], insulin [24], medin [25] and $\mathrm{A}_{\beta}$ [26].

The detailed investigation of the folding mechanisms is still challenging, since the intermediate is not a stable state and often inaccessible for adequate experimentation for the naturally involved peptides like $A_{\beta}$. 
Therefore, a model peptide with tailor-made aggregation behavior was developed by Pagel et al. [27] and modified to respond to certain environmental conditions [28]. The resulting peptide VW29 is able to adopt an $\alpha$-helical coiled coil conformation as well as $\beta$-sheet structures which ultimately fold into fibrils. Corresponding to the physiological conformation of many amyloidogenic peptides, it is unfoldedat low concentrations $(\leq 5 \mu \mathrm{M})$. The stabilization of the $\alpha$-helical conformation is advantageous for the study of $\alpha$-helical intermediates at the interface. An additional feature of the peptide is the possibility of transition metal ion complexation.

It is accepted that transition metal ions like $\mathrm{Zn}^{2+}$ or $\mathrm{Cu}^{2+}$ play a role in the aggregation of $A_{\beta}$, as they are present in the brain and are found in the pathological amyloid plaques [29] (review), $\mathrm{Zn}^{2+}$ and $\mathrm{Cu}^{2+}$ : [30-33], $\mathrm{Zn}^{2+}$ only: [34,35], $\mathrm{Cu}^{2+}$ only: [36-39]. Metal ion binding sites were introduced into the model peptide via histidine residues in an $\mathrm{i}, \mathrm{i}+2$ geometry. The binding of transition metal ions leads to the stabilization of either an unfolded conformation or of the $\beta$-sheet structure, accelerating the amyloid formation in bulk [28].

Interestingly, the different complexation geometries for $\mathrm{Zn}^{2+}$ and $\mathrm{Cu}^{2+}$ also influence the aggregation behavior of naturally occurring and model amyloidogenic peptides. While $\mathrm{Zn}^{2+}$ complexation is closely related to His residues and leads to rapid aggregation [40], the binding modes and role of $\mathrm{Cu}^{2+}$ are manifold [41-43]. We decided to investigate the inherent binding properties of the peptides apart from the amino terminal $\mathrm{Cu}^{2+}$ - and $\mathrm{Ni}^{2+}$ - (ATCUN) binding motif $[44,45]$ present in a range of metal binding peptides and proteins, but not in naturally occurring amyloidogenic peptides. The model peptide does not follow the ATCUN motif with a His in the third position from the $\mathrm{N}$ terminal part. Our model peptide with a metal ion ligation switch provides difference in conformational stability by sterical constraints. This general sterical effect is the mechanism under investigation in our study.

In addition to the influence of a hydrophobic interface on the folding behavior of the model peptide VW29, the complex interplay of the sometimes opposing influence of metal ion binding on the one hand and interaction with interfaces on the other hand is the focus of this study. In order to gain a first understanding of the behavior of the peptide at interfaces we chose a simple hydrophobic-hydrophilic interface, the air-water interface. We will present a structural study of surface layers of VW29 adsorbed at the air-water interface without the presence of metal ions and also complexed to $\mathrm{Zn}^{2+}$ or $\mathrm{Cu}^{2+}$, respectively.

Infrared reflection absorption spectroscopy measurements (IRRAS) have been carried out to investigate the time-dependent conformational behavior of the model peptide at the interface. The compression state of the adsorption layer was changed to monitor possible changes in the orientation of the peptide at the interface, and the influence of the binding of $\mathrm{Zn}^{2+}$ and $\mathrm{Cu}^{2+}$ was studied. For comparison, circular dichroism spectra (CD) of the corresponding bulk system were taken to prove the initial conformation of the peptide.

Surface-sensitive methods like grazing incidence X-ray diffraction (GIXD) allow us to evaluate the geometrical properties of the $\beta$-sheet layer at the interface. This information is complemented by X-ray reflectivity data, revealing the layer structure at the interface.

\section{Materials and methods}

All solutions were prepared using Milli-Q Millipore water with a resistivity of $18.2 \mathrm{M} \Omega \mathrm{cm}$.

\subsection{Materials}

VW29 was synthesized and purified as in [28] and used after removal of trifluoroacetate (TFA) (lyophilized three times with $0.5 \mathrm{mM} \mathrm{HCl}$ and once with water [46]). The molecular weight is $3349 \mathrm{~g} / \mathrm{mol}$. The peptide was dissolved in hexafluoroisopropanol
(HFIP) (Aldrich) (1 mg per $\mathrm{mL}$ ) to revert possible aggregation, dried in vacuum or under $\mathrm{N}_{2}$-stream directly before being dissolved in $10 \mathrm{mM}$ PBS (Fluka) containing $150 \mathrm{mM} \mathrm{NaCl}$ (Fluka, tempered at $600{ }^{\circ} \mathrm{C}$ before use) (no $\mathrm{NaCl}$ addition for $\mathrm{CD}$ measurements) and the corresponding concentration of metal ions ( 0 to $2 \mu \mathrm{M})$ at $\mathrm{pH} 7.4$ to yield a $0.3 \mu \mathrm{M}$ peptide solution. The solution was used immediately, shaking was avoided to prevent aggregation. $\mathrm{ZnCl}_{2}$ (Sigma) and $\mathrm{CuCl}_{2}$ (Fluka) were added from aqueous stock solutions of $1 \mathrm{mM}$ without further purification.

\subsection{Methods}

\subsubsection{Film balance measurements}

To record $\pi-t$ and $\pi$-A isotherms, a polytetrafluoroethylene (PTFE) Langmuir trough equipped with a micro balance (R\&K, Potsdam, Germany) and filter paper Wilhelmy plate was used and thermostatted at $20^{\circ} \mathrm{C}$ (E1 Medingen, Leipzig, Germany).

The peptide solution (10 mM phosphate buffer saline (PBS), $\mathrm{pH}$ $7.4,150 \mathrm{mM} \mathrm{NaCl}$ ) was filled into the trough and the adsorption isotherm was recorded. Monolayers were compressed symmetrically from two sides with a speed of $8.2 \mathrm{~cm}^{2} / \mathrm{min}$.

\subsection{2. $C D$}

Circular dichroism (CD) spectra confirmed the initial peptide conformation in solutions containing very low amounts of peptide, such as those used in the adsorption experiments. Peptide concentration was $5 \mu \mathrm{M}$. The sample mount of a Jasco J-715 CD spectrophotometer was thermostatted at $20^{\circ} \mathrm{C}$. Spectra were taken in the interval between $190 \mathrm{~nm}$ and $240 \mathrm{~nm}$ with a step resolution of $0.5 \mathrm{~nm}$ and a bandwidth of $1 \mathrm{~nm}$. The scanning rate was $50 \mathrm{~nm} / \mathrm{min}$ with a response time of $1 \mathrm{~s}$. To improve the signal-to-noise ratio a Suprasil Quartz-cuvette (Hellma GmbH, Muellheim, Germany) with a path length of $1 \mathrm{~cm}$ was used and 20 scans were accumulated. After the subtraction of buffer spectra, the mean residue molar ellipticity $\theta_{R}$ [deg $\mathrm{cm}^{2} / \mathrm{dmol}$ ] was calculated from the spectra by taking into account the respective concentration and pathlength. The spectra are not smoothed.

\subsubsection{IRRAS}

Infrared reflection absorption spectra (IRRA spectra) were recorded using an IFS 66 FT-IR spectrometer (Bruker, Ettlingen, Germany) and an external reflectance unit containing the film balance trough (R\&K, Potsdam, Germany) inside a container flushed with dry air to stabilize the relative humidity in the optical path. The trough system comprises a sample trough with two movable barriers and a reference trough to allow recording sample and reference spectra within short time ranges using a shuttling technique. Before hitting the water surface, the beam is polarized by a KRS- 5 wire grid polarizer to create parallel (p) or perpendicular ( $s$ ) polarized light. The incidence angle was varied between $30^{\circ}$ and $70^{\circ}$ relative to the normal of the surface. The use of mirrors allows the infrared beam from the external port of the spectrometer to hit the water surface at an adjustable angle of incidence. After reflection from the water surface, the beam is collected at the same angle and led to a narrow band Mercury Cadmium Telluride (MCT) detector cooled with liquid nitrogen. Reflectance-absorbance spectra with a resolution of $8 \mathrm{~cm}^{-1}$ were obtained using ${ }^{-} \lg \left(R / R_{0}\right)$, with $R$ being the reflectance of the sample and $R_{0}$ the reflectance of the reference, the surface of the respective buffer solution. For each single beam spectrum with p-polarized light 400 scans (200 scans for s-polarized light, scanner velocity $20 \mathrm{kHz}$ ) were added, apodized using Blackman-Harris 3-term function and fast Fourier transformed after one level of zero filling. Before representation, all spectra were corrected for atmospheric interference using the OPUS software and baseline corrected using a constant value. The spectra are not smoothed. $[47,48]$. 


\subsubsection{GIXD, X-ray reflectivity}

Grazing incidence X-ray diffraction and X-ray reflectivity were performed at the liquid surface diffractometer of the undulator beam line BW1 at HASYLAB, (DESY, Hamburg, Germany) equipped with a Langmuir trough with a single movable barrier and a micro balance with filter paper Wilhelmy plate. The trough was thermostatted at $20{ }^{\circ} \mathrm{C}$ and its hermetic container was flushed with He. The synchrotron beam was monochromated by a beryllium (002) crystal (wavelenght: $\lambda \approx 1.3 \AA$ ) before striking the liquid sample surface at an incidence angle of $\alpha_{i}=0.85 \cdot \alpha_{c r}=0.85 \cdot 0.13^{\circ}\left(\alpha_{c r}\right.$ : critical angle for total external reflection).

For grazing incidence X-ray diffraction (GIXD) a linear positionsensitive detector (OED-100-M, Braun, Garching, Germany) was rotated around the sample to detect the intensity of the diffracted beam as a function of the vertical and horizontal scattering angles $\left(\alpha_{f}\right.$ and $2 \theta$ ). A soller collimator was located between the sample and the detector. The Bragg rods and Bragg peaks were background subtracted before evaluating peak positions and Full Width at Half Maximum values. The vertical and horizontal scattering vector components were calculated using $Q_{z}=2 \pi / \lambda \sin \left(\alpha_{f}\right)$ and $Q_{x y}=4 \pi / \lambda \sin (2 \theta / 2)$.

For X-ray reflectivity, the vertical scattering vector component $q_{z}=(4 \pi / \lambda) \sin \alpha_{r}$ in the interval $0.01 \AA^{-1}$ to $0.85 \AA^{-1}$ was recorded as a function of the vertical incidence angle $\alpha_{i}$ with the help of a NaI scintillation detector, while the vertical reflection angle equals the vertical incidence angle $\alpha_{r}=\alpha_{i}$. The reflectivity was normalized to the FRESNEL reflectivity $\left(R / R_{F}\right)$. To access the electron density profile normal to the interface and normalized to water $\rho / \rho_{\text {water }}$, a model independent approach including linear combinations of b-splines was used. $[49,50]$ Afterwards the thicknesses, electron densities and roughnesses of a pile of homogeneous boxes were fitted to the electron density profile.

\section{Results and discussion}

VW29 (Fig. 1) is a peptide designed to study the very early stages of amyloid formation connected to neurodegenerative diseases like Alzheimer's or Parkinson's disease [28]. It does not follow specific motifs of naturally occurring peptides, but is designed to have distinct

\section{LKVELEKLLKSELLVVL̈HSHKEKLKSEL-OH}
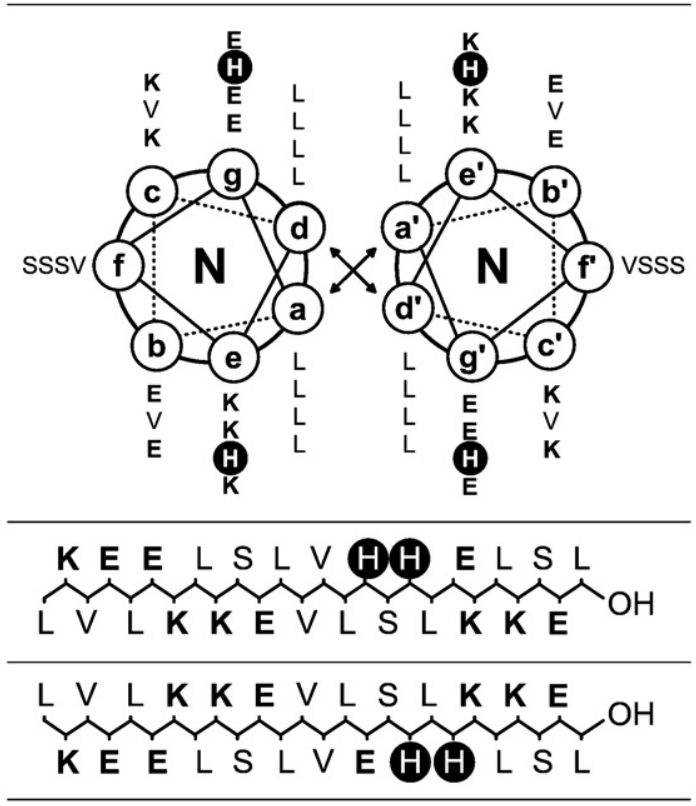

Fig. 1. Structure of VW29 in $\alpha$-helical coiled coil and as $\beta$-sheet. [28]. secondary structure propensities and to react on defined triggers. In phosphate buffer at $\mathrm{pH} 7.4$ (below the pI of the peptide of $\approx 9$ ) it comprises three stable secondary structures depending on concentration and time. At very low concentrations like those used for adsorption experiments $(\leq 5 \mu \mathrm{M})$, it adopts a mainly unfolded structure. At higher concentrations $(100 \mu \mathrm{M})$ it is $\alpha$-helical, but changes to a $\beta$-sheet structure after some time. Maltseva et al. found that the conformation of $A \beta$ does not change upon addition of salt [19]. Accordingly, we assume that the conformation of VW29 is insensitive to ionic strength. In order to assess the role transition metal ions play in amyloid formation, the peptide is equipped with two histidine binding sites. The binding of $\mathrm{Cu}^{2+}$ or $\mathrm{Zn}^{2+}$ to the peptide in bulk results in a stabilization of the unfolded conformation in the former case and accelerated amyloid formation in the latter [28].

In VW29, an $\alpha$-helical coiled coil conformation is used to define and stabilize an $\alpha$-helical conformation. As shown in the upper part of Fig. 1, this is achieved using the hydrophobic leucin zipper motive (positions a, d, $\mathrm{a}^{\prime}$ and $\mathrm{d}^{\prime}$ ) as well as by matching opposite charges in the $g$ and $\mathrm{e}^{\prime}$ (e and $\mathrm{g}^{\prime}$ ) as well as in the $\mathrm{g}$ and $\mathrm{c}(\mathrm{b}$ and $\mathrm{e}$ ) positions of a coiled coil [51-53]. A putative $\beta$-sheet arrangement is shown in the lower part of Fig. 1. There is no pronounced hydrophobic or hydrophilic face, but the position of the His residues defines two sides of the $\beta$-sheet (Fig. 1 lower part).

The focus of this study is the aggregation behavior of VW29 at hydrophobic surfaces, restricted to two dimensions. Therefore the surface activity of VW29 was investigated using the Langmuir technique and a very simple hydrophobic model surface, the airwater interface. VW29 is highly surface active. With peptide concentrations of $0.4 \mu \mathrm{M}$ or $0.3 \mu \mathrm{M}$ in the subphase, the equilibrium surface pressure is $\approx 20 \mathrm{mN} / \mathrm{m}$ (Fig. 2). Only the adsorption kinetics change. IRRAS and X-ray experiments are carried out using $0.3 \mu \mathrm{M}$ peptide solutions. The equilibrium surface pressure is reached after two hours of adsorption. The surface layer is compressible indicating slow desorption kinetics.

3.1. CD Spectroscopy - time and concentration dependence of secondary structure transformations - characterization of starting conformation

Circular dichroism of VW29 samples was used to estimate the conformation of the peptide in bulk and revealed a concentrationdependent aggregation behavior.

At very high concentrations $(500 \mu \mathrm{M})$, the peptide aggregates immediately after dissolution. This is also indicated by the turbidity of the aqueous solution. Solid aggregates sediment or give rise to light scattering [54] and do not contribute to the CD signal resulting in very low intensities. This effect cannot be quantified (data not shown), it does not occur at concentrations below $500 \mu \mathrm{M}$ and in the time scales relevant for the interface experiments.

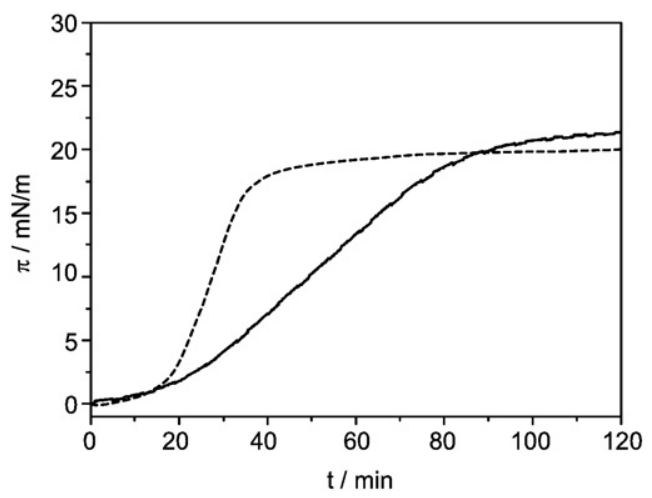

Fig. 2. Time-dependent surface pressure $\pi$ while VW29 is adsorbing to the air-water interface (solid line $0.3 \mu \mathrm{M}$ VW29, dashed line $0.4 \mu \mathrm{M}$ VW29, both $20^{\circ} \mathrm{C}, 10 \mathrm{mM}$ PBS pH 7.4, $150 \mathrm{mM} \mathrm{NaCl}$ ). 
In peptide samples containing $100 \mu \mathrm{M}$ VW29, the peptide adopts its stable $\alpha$-helical presumably coiled coil conformation immediately after dissolution, as indicated by the two minima at $208 \mathrm{~nm}$ and $220 \mathrm{~nm}$, and a maximum at $190 \mathrm{~nm}$ (Fig. 3). At a concentration of $100 \mu \mathrm{M}$ the peptide stays in an $\alpha$-helical conformation for at least 3 days.

Pagel et al. [28] found a transition of VW29 from unfolded to $\beta$-sheet within 5 days. Compared to our work, this study was carried out without pretreatment of the peptide in HFIP to destroy preexisting aggregates.

At bulk concentrations below $100 \mu \mathrm{M}$ the initial conformation of VW29 is not $\alpha$-helical, but unfolded. At a peptide concentration of $10 \mu \mathrm{M}$, no change of secondary structure was detected within 3 days. At a concentration of $5 \mu \mathrm{M}$ the peptide stays in an unfolded conformation for at least 3 days (Fig. 4).

VW29 is designed to react to transition metal ion complexation with changed aggregation behavior. At high concentrations $(100 \mu \mathrm{M})$ of VW29 Pagel et al. [28] found an accelerated $\beta$-sheet formation due to $\mathrm{Zn}^{2+}$ ion complexation. However, at low concentrations ( $\left.5 \mu \mathrm{M}\right)$, still above the concentrations used for adsorption experiments, we observed unfolded peptides complexed with $\mathrm{Cu}^{2+}$ or $\mathrm{Zn}^{2+}$ and no signs of an onset of aggregation for at least 2 days (data not shown). This finding is independent of the added amount of metal ions. Experiments were carried out with molar peptide: metal ion ratios from 1:0.25 to $1: 1.5$, covering a range from substoichiometric metal ion complexation to metal ion excess (data not shown).

At all these conditions (peptide concentrations higher than the ones used for adsorption and various metal ion complexation), aggregation does not occur within time scales of the experiments carried out with adsorbed peptide layers at the air-water interface (maximum of 2 days), therefore we consider that all observed conformational changes are the result of interface effects.

\subsection{IRRAS - surface triggers $\beta$-sheet formation, heterogeneous nucleation}

A very powerful tool to examine the secondary structure of peptides as surface layers is infrared reflection absorption spectroscopy. The reflected beam probes the enriched sample mainly at the interface and thus enhances sensitivity.

In the so-called amide region of the IR spectra, several bands can be assigned to the different secondary structure elements peptides can adopt. Bands at $1630 \mathrm{~cm}^{-1}$ are due to $\beta$-sheets, when shifted toward lower wavenumbers like $1620 \mathrm{~cm}^{-1}$ the $\beta$-sheets are aggregated. $\alpha$-helices result in a rather narrow band at $1650 \mathrm{~cm}^{-1}$ and unfolded peptide chains vibrate at $1655 \mathrm{~cm}^{-1}$, resulting in a very broad band. The discrimination of unfolded and $\alpha$-helical structures is only possible using spectra taken at different angles of incidence of the infrared beam below and above the Brewster angle [13,55-60].

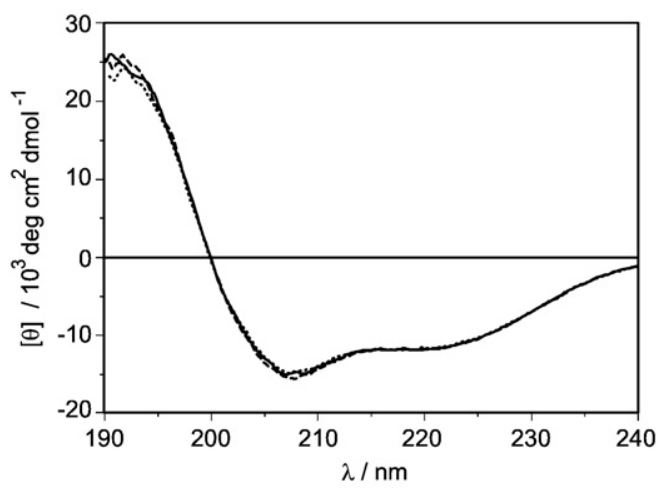

Fig. 3. CD spectra of VW29 $100 \mu \mathrm{M}$, solid line $0 \mathrm{~h}$, dashed line $24 \mathrm{~h}$, dotted line $48 \mathrm{~h}$ after dissolution $\left(20^{\circ} \mathrm{C}, 10 \mathrm{mM} \mathrm{PB}, \mathrm{pH} 7.4\right)$.

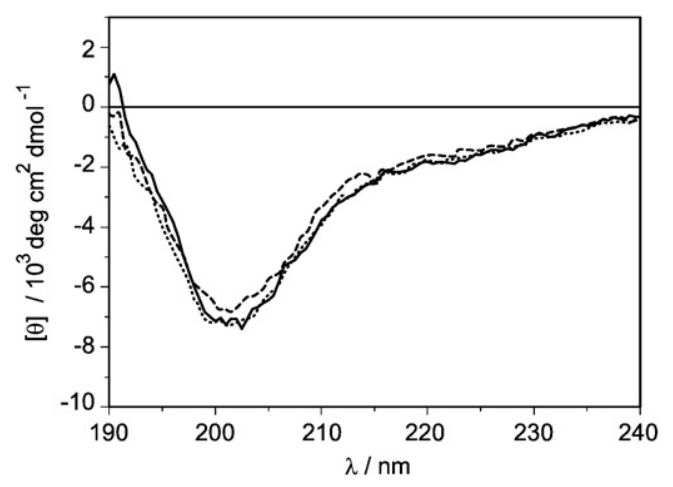

Fig. 4. CD spectra of VW29 $5 \mu \mathrm{M}$, solid line $0 \mathrm{~h}$, dashed line $24 \mathrm{~h}$, dotted line $48 \mathrm{~h}$ after dissolution $\left(20^{\circ} \mathrm{C}, 10 \mathrm{mM} \mathrm{PB}, \mathrm{pH} 7.4\right)$.

IR reflection absorption spectra were taken during the adsorption of the peptide to the air-water interface, during the subsequent $24 \mathrm{~h}$ and after compression of the equilibrium layer to $30 \mathrm{mN} / \mathrm{m}$ (Fig. 5). Spectra depending on the angle of incidence of the IR beam were taken. They allow the determination of orientations and will be presented separately. In this study we focus on the time-dependent change of peptide secondary structure, the effect of metal ion complexation and compression. As proven by CD spectroscopy, the initial conformation of the peptide is unfolded. However, VW29 is adsorbing to the surface in $\alpha$-helical conformation, as we observed narrow vibration bands at $1655 \mathrm{~cm}^{-1}$. This could be confirmed by additional measurements with the angle of incidence for the incoming and reflected beam above the Brewster angle. With the structure of the peptide in mind, we assume that the highly hydrophobic side of a single peptide helix lying flat at the surface points toward the hydrophobic air (Fig. 1).

This $\alpha$-helical layer is stable for $6 \mathrm{~h}$ up to $24 \mathrm{~h}$ depending on random preparation effects. Then a second band at $1624 \mathrm{~cm}^{-1}$ appears and increases during the next hours accompanied by a decrease of intensity at $1655 \mathrm{~cm}^{-1}$. This process corresponds to the formation of $\beta$-sheet structure out of $\alpha$-helices. As measurements at different angles of incidence below and above the Brewster angle and GIXD data (see Section 3.3) indicate, the $\beta$-sheets lie flat on the surface. A detailed study of orientations will be presented separately. The compression of a $\beta$-sheet layer results in a higher amount of material per surface area unit and leads to an increase of intensity of the amide I bands without changing their relative intensities. However, the relative intensity of the amide II band decreases for p-polarized but increases for s-polarized light. This finding indicates a

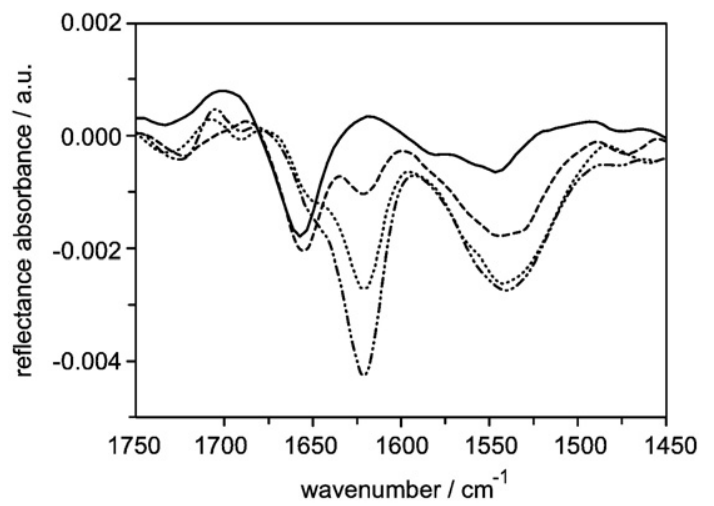

Fig. 5. Time-dependent IRRA spectra of VW29 at the air-water interface at equilibrium surface pressure $\pi \approx 20 \mathrm{mN} / \mathrm{m}$, solid line: $1 \mathrm{~h}$ after start of adsorption, dashed line $10 \mathrm{~h}$ after adsorption, dotted line $24 \mathrm{~h}$ after adsorption and dash-dotted line $1 \mathrm{~h}$ after compression to $\pi=30 \mathrm{mN} / \mathrm{m}$ taken with p-polarized light and an incidence angle of $40^{\circ}$ (0.3 $\mu \mathrm{M}$ VW29, $20^{\circ} \mathrm{C}, 10 \mathrm{mM}$ PBS, $\mathrm{pH}$ 7.4, $\left.150 \mathrm{mM} \mathrm{NaCl}\right)$. 
change of orientation of the peptide. The dichroic ratio $I_{p} / I_{s}$ of the band at $1624 \mathrm{~cm}^{-1}$, a measure of orientation of the peptides relative to each other, changes from 1.3 before to 2.2 after compression of the layer.

A compression of a layer with a lower $\beta$-sheet content results in the same process of growth of the band at $1624 \mathrm{~cm}^{-1}$, accompanied by a decrease of intensity at $1655 \mathrm{~cm}^{-1}$ in a shorter period of time. We conclude that the further increase of concentration at the surface due to the compression triggers the transition to $\beta$-sheet.

Even after $\beta$-sheet formation the spectra show $\alpha$-helical (or unfolded) as well as $\beta$-sheet signals (Fig. 5), indicating that there is no complete transformation or a two layer structure is formed. One layer would consist of a $\beta$-sheet structure. Subsequently adsorbing peptides, forming a second layer underneath, would therefore not sense a hydrophobic air-water interface that means there is no trigger for a $\beta$-sheet formation. The described effect is still under investigation. We think that the $\beta$-sheet formation may take more time than can be reasonably covered by measurements at liquid surfaces.

The addition of $\mathrm{Cu}^{2+}$ ions to the peptide solution before adsorption results in similar IRRA spectra (Fig. 6). The spectra of the initial layer show a strong band at $1655 \mathrm{~cm}^{-1}$, indicating a high $\alpha$-helical content. However, the growth of a band at $1624 \mathrm{~cm}^{-1}$ begins very early, even before the adsorption reached equilibrium. A shoulder at $1624 \mathrm{~cm}^{-1}$ appears after one hour of adsorption. The $\beta$-sheet transition is almost complete after $10 \mathrm{~h}$. As in the case of uncomplexed peptides, a small shoulder at $1655 \mathrm{~cm}^{-1}$ remains and does not disappear during the following day. Compression leads to higher intensities of the already existing bands. This is probably a result of the $\beta$-sheet layer taking an in-plane orientation that makes the excitation of the transition dipole moments more efficient.

Complexation with $\mathrm{Zn}^{2+}$ gives qualitatively the same results. The $\beta$-sheet formation is even accelerated. It starts after $30 \mathrm{~min}$ and evolves fast. Even though with $C D$ spectroscopy we proved an unfolded initial conformation, the spectra taken after one hour of adsorption include bands at $1655 \mathrm{~cm}^{-1}$ and $1624 \mathrm{~cm}^{-1}$ with similar intensities (not shown). This finding is in agreement with Bush et al. [40], who reported very fast aggregation upon addition of $\mathrm{Zn}^{2+}$ to $\mathrm{A}_{\beta}$ peptide in a bulk system at higher concentrations. We conclude that the increase of concentration due to enrichment at the interface is enough to trigger an inmediate $\beta$-sheet formation. The increase of the dichroic ratio $I_{p} / I_{s}$ of the band at $1624 \mathrm{~cm}^{-1}$ from 2.5 before to 4.2 after compression indicates an additional orientation of $\beta$-sheets relative to each other.

One sample was doped with a very small amount of a phospholipid (corresponding to a surface coverage in the order of $10^{4} \AA^{2} /$ molecule). The ester $\nu(\mathrm{CO})$-vibration band at $1724 \mathrm{~cm}^{-1}$ is growing very fast and simultaneously with the band for $\beta$-sheet upon compression (not

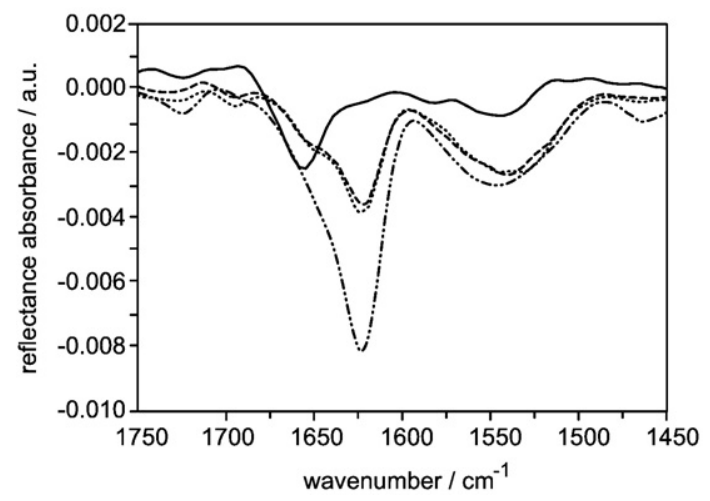

Fig. 6. Time-dependent IRRA spectra of VW29 complexed by $\mathrm{Cu}^{2+}$ at the air-water interface at equilibrium surface pressure $\pi \approx 20 \mathrm{mN} / \mathrm{m}$, solid line: $1 \mathrm{~h}$ after start of adsorption, dashed line $10 \mathrm{~h}$ after adsorption, dotted line $24 \mathrm{~h}$ after adsorption and dash-dotted line $1 \mathrm{~h}$ after compression to $\pi=30 \mathrm{mN} / \mathrm{m}$ taken with p-polarized light and an incidence angle of $40^{\circ}\left(0.3 \mu \mathrm{M}\right.$ VW29, $0.3 \mu \mathrm{M} \mathrm{Cu}^{2+}, 20^{\circ} \mathrm{C}, 10 \mathrm{mM} \mathrm{PBS}, \mathrm{pH} 7.4$, $150 \mathrm{mM} \mathrm{NaCl}$ ). shown), suggesting that heterogeneous nucleation facilitates the rapid conformational change to $\beta$-sheets. This might play a key role in the onset of $\beta$-sheet misfolding in more physiological conditions including more detailed membrane models like lipid layers. This effect was also applied by Muenter et al. using low amounts of stearic acid as seeds to trigger the self assembly of a peptide-polymer conjugate [61].

X-ray techniques like Grazing incidence X-ray diffraction and X-ray reflectivity were used to complement results obtained with infrared spectroscopy.

\subsection{GIXD - packing parameters and in-plane order of $\beta$-sheet layers}

Combining X-ray diffraction with a total reflection setup leads to a highly surface sensitive scattering technique. A synchrotron X-ray beam grazes the air-water surface on a Langmuir trough fulfilling total reflection conditions. Only ordered structures that are highly enriched by adsorption at the interface contribute to a two dimensional powder spectrum, omitting all influences of subphase material and therefore increasing the signal-to-noise ratio. The scattered intensity is detected by a positional sensitive detector which is rotated around the sample. Therefore the intensity of the diffracted beam as a function of the vertical and horizontal scattering angles is accessed and transformed into the vertical and horizontal scattering vector components. Grazing incidence X-ray diffraction was used to characterize the VW29 surface layer. Ordered $\beta$-sheet layers at the surface result in Bragg peaks at $Q_{x y}$ values, defined by the dimensions of the 2-dimensional repeat pattern. As IRRAS-measurements below and above the Brewster angle show and as indicated by $Q_{z}=0$, the $\beta$-sheets in the layer lie flat on the surface.

Interestingly the $\beta$-sheet formation differed depending on the added metal ions, as already indicated in the time-dependent IRRA experiments (Section 3.2) and found by Pagel et al. [28]. We used the presence of a typical Bragg peak with $Q_{x y} \approx 1.3 \AA^{-1}$ as evidence for ordered $\beta$-sheets at the interface. Without metal ion complexation VW29 only aggregates after compression of the surface layer to $30 \mathrm{mN} / \mathrm{m}$, the bilayer-monolayer correspondence pressure. With additional $\mathrm{Cu}^{2+}$ ions the peptide seems to aggregate immediately after adsorption to the interface, while $\mathrm{CD}$-spectra verified a stable unfolded conformation under similar conditions in bulk. In contrast, addition of $\mathrm{Zn}^{2+}$-ions results in a rather defined $\beta$-sheet layer. The evidence for this disappears after compression. As a disaggregation was not observed with IRRAS, we assume that the already existing ordered $\beta$-sheet aggregates are reoriented or destroyed. If the $\beta$-sheet crystal grows to extreme dimensions the powder conditions are not valid anymore. Depending on the orientation of this highly ordered $\beta$-sheet domain, the Bragg equation might not be fulfilled. Only by rotation of the trough system it would be possible to observe a diffraction pattern. However, this is not possible in the experimental setup used at HASYLAB. An additional orientation of $\beta$-sheets was also observed in the IRRAS spectra after compression. Another possibility is that the order of the $\beta$-sheet relative to each other is destroyed by compression.

Experiments at equilibrium surface pressure $(\pi \approx 20 \mathrm{mN} / \mathrm{m})$ and after compression to $30 \mathrm{mN} / \mathrm{m}$ typically revealed a peak corresponding to the repeat pattern perpendicular to the $\beta$-sheet at $Q_{x y} \approx 1.33 \AA^{-1}$ (Fig. 7). Using $d=2 \pi / Q_{x y}$ the $\beta$-sheet repeat distance was calculated to $d \approx 4.73 \AA$ for all layers which contained detectable $\beta$-sheets (Table 1 ).

In the case of $\mathrm{Cu}^{2+}$-complexed VW29 at $30 \mathrm{mN} / \mathrm{m}$, an additional end-to-end distance of $52.40 \AA$ indicated by a Bragg peak at $Q_{x y}=0.124 \AA^{-1}$ could be detected (Fig. 8 and Table 1 ). The two peaks can be indexed according to Lepere et al. [62], assuming a rectangular unit cell with the H-bond distance $a=4.73 \AA$ (peak (20)) and the longitudinal distance $b=52.40 \AA$ (peak (01)). The structure presumably consists of parallel $\beta$-sheets, as no indication for a repeat pattern with the double $\mathrm{H}$-bond distance was observed. The length of the unit cell does not correspond to the length of the peptide molecule in extended $\beta$-sheet conformation, indicating a structure where only 


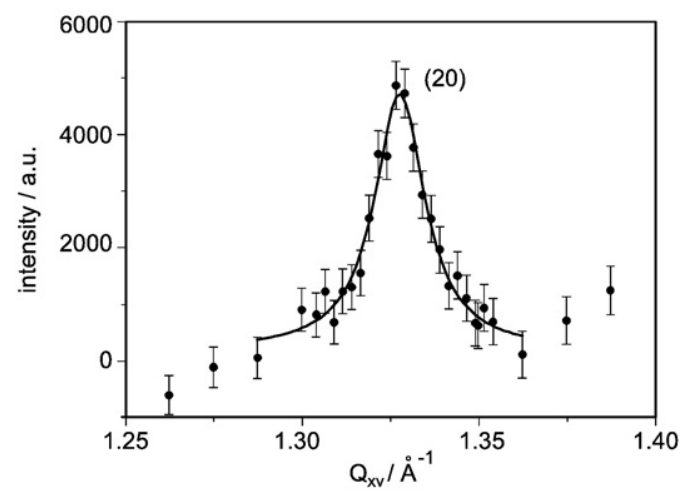

Fig. 7. Scattered intensity $I$, normalized to the incoming intensity $I_{0}$ versus the inplane component of the scattering vector $Q_{x y}$. The Bragg peak (20) is corresponding to the $\mathrm{H}$-bond distance in the $\beta$-sheet layer observed by GIXD of a VW29 surface layer $\left(0.3 \mu \mathrm{M}\right.$ VW29, $0.6 \mu \mathrm{M} \mathrm{Cu}{ }^{2+}$ in bulk, $20^{\circ} \mathrm{C}, 10 \mathrm{mM}$ PBS, pH 7.4, $\left.150 \mathrm{mM} \mathrm{NaCl}\right)$ compressed to $\pi=30 \mathrm{mN} / \mathrm{m}$.

parts of the molecule are incorporated into the $\beta$-sheet structure. Upon further compression, the surface pressure does hardly increase because some peptides desorb. Nevertheless we found the unit cell was compressible in the longitudinal direction (from $b=52.40 \AA$ to $b=50.63 \AA$ ) while the packing did not change in the interstrand $\beta$ sheet to $\beta$-sheet direction $a$.

The correlation lengths calculated using the Scherrer equation [63] differ according to the metal ions present in the sample. For non complexed VW29 at $30 \mathrm{mN} / \mathrm{m}$ it is $235 \AA$ indicating 50 aligned and H-bonded $\beta$-sheet strands with $4.73 \AA$ repeat distance. The uncompressed $\mathrm{Zn}^{2+}$ complexed sample exhibits a very high correlation length (exceeding the resolution of the experiment of $\approx 780 \AA$ ) perpendicular to the $\beta$-sheet strands. A large number of peptide molecules $(\geq 165)$ is aggregated at an equilibrium surface pressure of $21.5 \mathrm{mN} / \mathrm{m}$.

Upon compression of the VW29 layer containing $\mathrm{Cu}^{2+}$ ions, the correlation length decreases from $650 \AA$ to $280 \AA$ in direction perpendicular to the peptide backbone. This corresponds to 138 to 60 aligned and aggregated $\beta$-sheet strands. Longitudinal to the $\beta$-sheet direction the correlation length is about $280 \AA$, that is 5 units of repeat pattern of a $52 \AA$ peptide stretch. This longitudinal order does not change upon further compression and within $30 \mathrm{~min}$.

\subsection{X-ray reflectivity - layer structure influenced by metal ions}

The setup used for GIXD experiments with the synchrotron X-ray beam grazing the liquid sample surface was used to obtain X-ray reflectivity curves.

After normalization to FRESNEL reflectivity, the depicted electron density profiles (Fig. 9) were obtained without using model assumptions, but using a linear combination of b-splines following the approach of Pedersen and Hamley [49,50]. The profiles are normal to the interface starting with the electron density of air (0) and ending with the electron density of $\mathrm{H}_{2} \mathrm{O}$, which was 1 after normalization.

\section{Table 1}

$\beta$-sheet repeat distances, observed by GIXD of a VW29 surface layer $(0.3 \mu \mathrm{M}$ VW29, $0.6 \mu \mathrm{M} \mathrm{Cu}^{2+}$ or $\mathrm{Zn}^{2+}$ in bulk, $20^{\circ} \mathrm{C}, 10 \mathrm{mM}$ PBS, pH 7.4, $150 \mathrm{mM} \mathrm{NaCl}$ ) at equilibrium surface pressure $\pi \approx 20 \mathrm{mN} / \mathrm{m}$ and compressed to $\pi=30 \mathrm{mN} / \mathrm{m}$. $\left({ }^{*}\right)$ No Bragg peak was detected.

\begin{tabular}{|c|c|c|c|c|c|}
\hline & $\pi$ & $Q_{x y}$ & $Q_{x y}($ end-to-end) & $d$ & d (end-to end) \\
\hline & $/ \mathrm{mN} / \mathrm{m}$ & $\overline{/ \AA^{-1}}$ & $/ \AA^{-1}$ & $/ \AA ̊$ & $/ \AA ̊$ \\
\hline \multirow[t]{2}{*}{ VW29 } & 20 & $*$ & $*$ & $*$ & $*$ \\
\hline & 30 & 1.327 & * & 4.73 & * \\
\hline \multirow[t]{2}{*}{ VW29 $\mathrm{Zn}^{2+}$} & 21.5 & 1.322 & $*$ & 4.75 & $*$ \\
\hline & 30 & $*$ & $*$ & * & * \\
\hline \multirow[t]{2}{*}{ VW29 $\mathrm{Cu}^{2+}$} & 22 & 1.324 & $*$ & 4.75 & $*$ \\
\hline & 30 & 1.328 & 0.120 & 4.73 & 52.40 \\
\hline
\end{tabular}

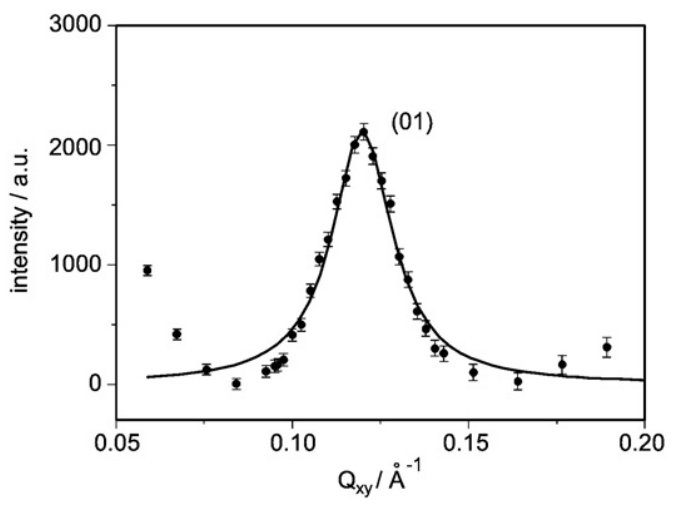

Fig. 8. Scattered intensity $I$, normalized to the incoming intensity $I_{0}$ versus the in-plane component of the scattering vector $Q_{x y}$. The Bragg peak (01) is corresponding to the longitudinal repeat distance in the $\beta$-sheet layer observed by GIXD of a VW29 surface layer $\left(0.3 \mu \mathrm{M}\right.$ VW29, $0.6 \mu \mathrm{M} \mathrm{Cu}{ }^{2+}$ in bulk, $\left.20^{\circ} \mathrm{C}, 10 \mathrm{mM} \mathrm{PBS}, \mathrm{pH} 7.4,150 \mathrm{mM} \mathrm{NaCl}\right)$ compressed to $\pi=30 \mathrm{mN} / \mathrm{m}$.

They could afterwards be fitted using a box model assuming a pile of homogeneous boxes of certain thickness $d$, electron density $\rho / \rho_{\mathrm{H}_{2} \mathrm{O}}$ and roughness of their boundaries (Table 2).

Peptide layers which result from adsorption without further compression differ according to the metal ion present in the sample (inset of Fig. 9). Compared to the pure peptide layer (solid line, maximum at 1.17), the maximum electron density $\rho / \rho_{\mathrm{H}_{2} \mathrm{O}}$ of both metal ion containing layers (dashed and dotted lines in Fig. 9, maxima at 1.19) are slightly higher. This is a strong indication for a contribution of the incorporated metal ions. Obviously, $\mathrm{Cu}^{2+}$ and $\mathrm{Zn}^{2+}$ have different binding properties, resulting in different structures of the surface layer. Although both samples exhibit $\beta$-sheet character in IRRAS and GIXD data, the two metal ion containing layers are markedly different. In the case of $\mathrm{Cu}^{2+}$ binding, the maximum electron density is shifted to a position closer to the subphase compared to the pure peptide layer. $\mathrm{Zn}^{2+}$-binding on the other hand leads to a shift of the maximal electron density to a position closer tothe air. The difference is maybe related to a preferred binding of $\mathrm{Zn}^{2+}$ ions on the face of the $\beta$-sheet layer containing the His residues and pointing toward the air, while $\mathrm{Cu}^{2+}$ is additionally able to bind to the peptide backbone [64], bending a distorted part of the $\beta$-sheet away from the air interface. Also the $\beta$-sheet layer could be oriented upside down, with the histidine binding sites and other putative binding sites pointing toward the water, exposing the other uncomplexed face to the air.

To describe the electron density profile of a pure peptide layer correctly, two boxes are necessary, but three boxes have a better correlation to the data (Table 2). The first box, pointing toward the air, has usually a thickness of about $5 \AA$ and an electron density lower than water or the acyl chain region of lipid layers. We therefore

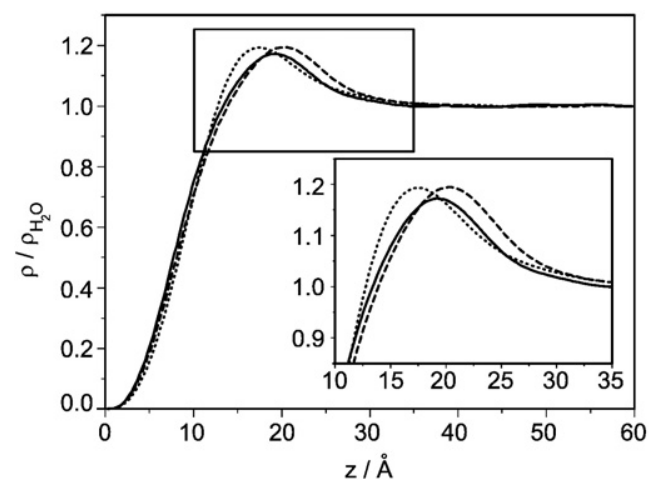

Fig. 9. Electron density profiles of VW29 layer without (solid line) and with $\mathrm{Cu}^{2+}$-ions (dashed line) or $\mathrm{Zn}^{2+}$-ions (dotted line), obtained by a model free sum of b-splines fit $[49,50]\left(20^{\circ} \mathrm{C}, 0.3 \mu \mathrm{M}\right.$ VW29, $0.6 \mu \mathrm{M} \mathrm{Me}{ }^{2+}, 10 \mathrm{mM} \mathrm{PBS}, \mathrm{pH} 7.4,150 \mathrm{mM} \mathrm{NaCl}$, $\pi=20 \mathrm{mN} / \mathrm{m}$ ). 
Table 2

Box model data for a pure VW29 layer and interacting with $\mathrm{Zn}^{2+}$ or $\mathrm{Cu}^{2+}$ at equilibrium pressure $\approx 20 \mathrm{mN} / \mathrm{m}$ and after compression to $30 \mathrm{mN} / \mathrm{m}, 1$ st box pointing toward air $2^{\text {nd }}$ box containing the main layer and metal ions, $3^{\text {rd }}$ box pointing toward subphase containing unstructured peptide ends.

\begin{tabular}{|c|c|c|c|c|c|c|}
\hline \multirow{2}{*}{$20 \mathrm{mN} / \mathrm{m}$} & \multicolumn{2}{|l|}{$1^{\text {st }}$ box } & \multicolumn{2}{|l|}{$2^{\text {nd }}$ box } & \multicolumn{2}{|c|}{$3^{r d}$ box } \\
\hline & & & & & & \\
\hline VW29 & $\mathrm{d} / \AA ̊$ & $\rho / \rho_{\mathrm{H}_{2} \mathrm{O}}$ & $\mathrm{d} / \AA ̊$ & $\rho / \rho_{\mathrm{H}_{2} \mathrm{O}}$ & $\mathrm{d} / \AA ̊$ & $\rho / \rho_{\mathrm{H}_{2} \mathrm{O}}$ \\
\hline Without $\mathrm{Me}^{2+}$ & 5.0 & 0.55 & 11.7 & 1.19 & 6.2 & 1.05 \\
\hline $\mathrm{Cu}^{2+}$ & 5.6 & 0.60 & 12.0 & 1.22 & 8.0 & 1.04 \\
\hline $\mathrm{Zn}^{2+}$ & 4.7 & 0.22 & 10.7 & 1.23 & 5.4 & 1.10 \\
\hline \multicolumn{7}{|l|}{$30 \mathrm{mN} / \mathrm{m}$} \\
\hline VW29 & $\mathrm{d} / \AA ̊$ & $\rho / \rho_{\mathrm{H}_{2} \mathrm{O}}$ & $\mathrm{d} / \AA ̊$ & $\rho / \rho_{\mathrm{H}_{2} \mathrm{O}}$ & $\mathrm{d} / \AA ̊$ & $\rho / \rho_{\mathrm{H}_{2} \mathrm{O}}$ \\
\hline Without $\mathrm{Me}^{2+}$ & 4.9 & 0.46 & 17.7 & 1.21 & 13.1 & 1.05 \\
\hline $\mathrm{Cu}^{2+}$ & 4.2 & 0.28 & 10.6 & 1.10 & 5.5 & 1.50 \\
\hline $\mathrm{Zn}^{2+}$ & 6.0 & 0.80 & 3.8 & 1.69 & 12.3 & 1.11 \\
\hline
\end{tabular}

assume that some peptide side chains point into the air. A second box presumably containing the $\beta$-sheet layer and the complexed metal ions has a thickness comparable to values found for $\beta$-sheets, with relatively small roughness and an electron density roughly matching theoretical calculations for a densely packed VW29 surface in the case of a pure peptide layer. In the case of compressed VW29 layers complexed by $\mathrm{Zn}^{2+}$, the second box close to the air has a very high electron density and low thickness. We assume that the metal ions are located there. In contrast to this, the $\mathrm{Cu}^{2+}$ complexed VW29 layer shows a rather thin box with high electron density closer to the water.

The third box limiting the peptide layer toward the water subphase has a very high roughness and electron density close to that of water in most cases. This is indicative of rather dilute and unordered layers. This part of the layer structure might correspond to the still remaining unordered or $\alpha$-helical content in the IRRA spectra after compression or after long incubation times (Figs. 5 and 6). In conclusion, there is a densely packed $\beta$-sheet layer at the surface and a layer beneath it which has an electron density similar to that of water. This might be formed by unordered peptide ends hanging unfolded into the water (explaining the shorter end-to-end distance found with GIXD (Table 1)) or a second adsorbed layer that interacts with the $\beta$-sheet layer and not with air so that it has no trigger to rearrange into $\beta$-sheets. In the complexed layers the metal ion is either situated in a defined layer close to the air $\left(\mathrm{Zn}^{2+}\right)$ or closer to the subphase $\left(\mathrm{Cu}^{2+}\right)$, that means bound to the upper or lower face of the $\beta$-sheet layer.

$\mathrm{Cu}^{2+}$ complexation of VW29 leads to a thicker surface layer at equilibrium pressure and in compressed state. As X-ray reflectivity only probes an average electron density profile, this could indicate a mixed layer of $\beta$-sheets as detected by GIXD and unordered or $\alpha$-helical peptides or a distortion of the $\beta$-sheet layer due to binding to binding sites apart from the histidine side chains.

After compression all surface layers become thicker. The $\mathrm{Cu}^{2+}$ containing layer is very thick compared to the pure peptide layer and the one containing $\mathrm{Zn}^{2+}$. The latter two become more similar upon compression, concerning the shape of the electron density profiles.

Without metal ions and after compression to $30 \mathrm{mN} / \mathrm{m}$ a $\beta$-sheet was detected by GIXD and IRRAS, but the layer structure is clearly different from the other ( $\beta$-sheet containing) samples. The second box has a thickness of almost $18 \AA$ And could indicate a second $\beta$-sheet layer just beneath or a mixed layer composed of $\beta$-sheets and $\alpha$-helices.

\section{Conclusion}

In this paper we have presented structural studies of an amyloidogenic model peptide interacting with the hydrophobic airwater interface. We additionally investigated the interplay of the two factors hydrophobic interface and transition metal ion binding on the conformation of the peptide. The peptide VW29 is designed to have a hydrophobic face in its $\alpha$-helical conformation in order to be able to form a stable coiled coil structure in bulk. On the other hand it comprises $\beta$-sheet stabilizing features. Additionally it is equipped with histidine binding sites, which favor a certain geometry upon transition metal ion complexation.

The peptide is surface active, its equilibrium surface pressure amounts to $\approx 20 \mathrm{mN} / \mathrm{m}$ for buffered solutions with concentrations in the $\mu \mathrm{M}$-range. Using $\mathrm{CD}$ spectroscopy we found the conformation of the peptide in bulk is concentration-dependent. At high concentrations $(500 \mu \mathrm{M})$ the peptides aggregates immediately, while at $100 \mu \mathrm{M}$ it is $\alpha$-helical for at least two days. At the concentrations used for further studies ( $\leq 5 \mu \mathrm{M}$ ) however, VW29 is unfolded over the time range of two days. This conformation is not altered by addition of $\mathrm{Cu}^{2+}$ or $\mathrm{Zn}^{2+}$ to the solutions $\left(c_{\text {peptide }}=5 \mu \mathrm{M}\right)$ in substoichiometric to excess concentrations. Although in bulk $\left(c_{\text {peptide }} \leq 5 \mu \mathrm{M}\right)$, the peptide adopts an unfolded conformation, it adsorbs to the airwater interface in an $\alpha$-helical conformation as proven by IRRAS. The peptide enriched at the interface starts to transform to $\beta$-sheets after some hours. The $\beta$-sheet formation is accelerated by an additional orientation of the peptides relative to each other by compression of the surface layer, but an $\alpha$-helical or unfolded part of the peptide still remains evident in the IRRA spectra. We suppose that the $\beta$-sheet formation is uncomplete within reasonable experimentation time. Potentially, one or both ends of the peptide do not contribute to the $\beta$-sheet or a second peptide layer adsorbs underneath the surface layer and stays unfolded or $\alpha$-helical. Heterogeneous nucleation enhances $\beta$-sheet formation and may play an important role in processes involving more complex membrane models or cell membranes. The investigation of the surface layer structure by GIXD revealed typical repeat patterns for interstrand $\beta$-sheet distances of $d \approx 4.73 \AA$. Based on X-ray reflectivity data, the surface layer can be characterized by a three layer structure: one layer of amino acid side chains pointing toward the air, a second layer containing the peptide in its helical or $\beta$-sheet conformation and a third layer consisting of unfolded or $\alpha$-helical ends of the peptide hanging into the water.

The effects the metal ions $\mathrm{Cu}^{2+}$ and $\mathrm{Zn}^{2+}$ impose on this conformational behavior depend on the binding modes of the ions, but both accelerate the $\beta$-sheet formation at the interface. Especially $\mathrm{Zn}^{2+}$ ions cause highly ordered and aggregated structures at the surface as found by GIXD. Ordered domains are formed of 50 (no metal ion $), \approx 140\left(\mathrm{Cu}^{2+}\right)$ up to $\approx 160\left(\mathrm{Zn}^{2+}\right)$ parallel aligned peptide strands. The repeat pattern of a $\mathrm{Cu}^{2+}$-complexed $\beta$-sheet layer indicates that one or both ends of the peptide are not contained in the $\beta$-sheet. Concerning the structure perpendicular to the interface, addition of $\mathrm{Cu}^{2+}$ results in an unexpected thick layer, probably because $\mathrm{Cu}^{2+}$ distorts the peptide chain away from the interface by binding to the peptide backbone or $\mathrm{N}$ terminus. Maybe $\alpha$-helices, with their larger diameter, contribute to the structure of a mixed surface layer. The $\mathrm{Cu}^{2+}$ ions are located underneath the peptide layer, pointing toward the water subphase. $\mathrm{Zn}^{2+}$ ions however, lead to a very fast $\beta$-sheet formation and very high in-plane order of the resulting layers. The $\mathrm{Zn}^{2+}$ ions reside together with the peptide in a defined layer close to the air interface.

All these considerations lead to a possible model of the peptide layer at the interface as depicted schematically in Fig. 10.

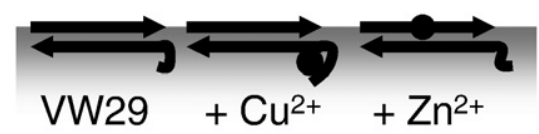

Fig. 10. Possible structure of the VW29 peptide layers at the air-water interface; without metal ions or complexed with $\mathrm{Cu}^{2+}$ or $\mathrm{Zn}^{2+}$ ions respectively. 


\section{Acknowledgements}

The authors like to thank DESY (Hamburg, Germany) for beam time, Selina Schimka and Richard Hinze for CD experiments and Benjamin Gaede for language service.

\section{References}

[1] M.P. Lambert, A.K. Barlow, B.A. Chromy, C. Edwards, R. Freed, M. Liosatos, T.E. Morgan, I. Rozovsky, B. Trommer, K.L. Viola, P. Wals, C. Zhang, C.E. Finch, G.A. Krafft, W.L. Klein, Diffusible, nonfibrillar ligands derived from abeta1-42 are potent central nervous system neurotoxins, Proc Natl Acad Sci U S A 95 (1998) 6448-6453.

[2] D.M. Hartley, D.M. Walsh, C.P. Ye, T. Diehl, S. Vasquez, P.M. Vassilev, D.B. Teplow, D.J. Selkoe, Protofibrillar intermediates of amyloid beta -protein induce acute electrophysiological changes and progressive neurotoxicity in cortical neurons, J. Neurosci. 19 (1999) 8876-8884.

[3] D.M. Walsh, I. Klyubin, J.V. Fadeeva, W.K. Cullen, R. Anwyl, M.S. Wolfe, M.J. Rowan, D.J. Selkoe, Naturally secreted oligomers of amyloid beta protein potently inhibit hippocampal long-term potentiation in vivo, Nature (London, U. K.) 416 (2002) 535-539.

[4] C.A. McLean, R.A. Cherny, F.W. Fraser, S.J. Fuller, M.J. Smith, K. Beyreuther, A.I. Bush, C.L. Masters, Soluble pool of abeta amyloid as a determinant of severity of neurodegeneration in alzheimer's disease, Ann. Neurol. 46 (1999) 860-866.

[5] K.A. Conway, S.-J. Lee, J.-C. Rochet, T.T. Ding, R.E. Williamson, J. Lansbury, T. Peter Acceleration of oligomerization, not fibrillization, is a shared property of both alpha-synuclein mutations linked to early-onset Parkinson's disease: implications for pathogenesis and therapy. Proc. Natl. Acad. Sci. U. S. A. 97 (2000) 571-576.

[6] R. Kayed, E. Head, J.L. Thompson, T.M. McIntire, S.C. Milton, C.W. Cotman, C.G. Glabe, Common structure of soluble amyloid oligomers implies common mechanism of pathogenesis, Science (Washington, DC, U. S.) 300 (2003) 486-489.

[7] K. Matsuzaki, Physicochemical interactions of amyloid beta -peptide with lipid bilayers, Biochim. Biophys. Acta, Biomembr 1768 (2007) 1935-1942.

[8] R.M. Murphy, Kinetics of amyloid formation and membrane interaction with amyloidogenic proteins, Biochim. Biophys. Acta-Biomembr. 1768 (8) (2007) 1923-1934.

[9] V. Koppaka, P.H. Axelsen, Accelerated accumulation of amyloid beta proteins on oxidatively damaged lipid membranes, Biochemistry 39 (2000) 10011-10016.

[10] J.W. Pettegrew, K. Panchalingam, R.L. Hamilton, R.J. McClure, Brain membrane phospholipid alterations in alzheimer's disease, Neurochem. Res. 26 (2001) 771-782.

[11] T. Kiyota, S. Lee, G. Sugihara, Design and synthesis of amphiphilic alpha-helica model peptides with systematically varied hydrophobic-hydrophilic balance and their interaction with lipid- and bio-membranes, Biochemistry 35 (1996) 13196-13204.

[12] E. Terzi, G. Hoelzemann, J. Seelig, Interaction of alzheimer beta-amyloid peptide (1-40) with lipid membranes, Biochemistry 36 (1997) 14845-14852.

[13] C. Schladitz, E.P. Vieira, H. Hermel, H. Mohwald, Amyloid-beta-sheet formation at the air-water interface, Biophys. J. 77 (1999) 3305-3310.

[14] M. Bokvist, F. Lindstrom, A. Watts, G. Grobner, Two types of alzheimer's betaamyloid (1-40) peptide membrane interactions: Aggregation preventing transmembrane anchoring versus accelerated surface fibril formation, J. Mol. Biol. 335 (4) (2004) 1039-1049.

[15] S. Rocha, R. Krastev, A.F. Thuenemann, M.C. Pereira, H. Moehwald, G. Brezesinski, Adsorption of amyloid beta-peptide at polymer surfaces: a neutron reflectivity study, Chem. Phys. Chem. 6 (2005) 2527-2534.

[16] D.H.J. Lopes, A. Meister, A. Gohlke, A. Hauser, A. Blume, R. Winter, Mechanism of islet amyloid polypeptide fibrillation at lipid interfaces studied by infrared reflection absorption spectroscopy, Biophys. J. 93 (2007) 3132-3141.

[17] I. Brovchenko, G. Singh, R. Winter, Aggregation of amyloidogenic peptides near hydrophobic and hydrophilic surfaces, Langmuir 25 (2009) 8111-8116.

[18] M. Lepere, A.H. Muenter, C. Chevallard, P. Guenoun, G. Brezesinski, Comparative IR and X-ray studies of natural and model amyloid peptides at the air/water interface, Colloids Surf., A 303 (2007) 73-78.

[19] E. Maltseva, A. Kerth, A. Blume, H. Moehwald, G. Brezesinski, Adsorption of amyloid beta (1-40) peptide at phospholipid monolayers, Chem. Bio. Chem. 6 (2005) 1817-1824.

[20] Y. Fezoui, D.B. Teplow, Kinetic studies of amyloid beta-protein fibril assembly. Differential effects of alpha-helix stabilization, J. Biol. Chem. 277 (2002) 36948-36954.

[21] M.D. Kirkitadze, M.M. Condron, D.B. Teplow, Identification and characterization of key kinetic intermediates in amyloid beta-protein fibrillogenesis, J. Mol. Biol. 312 (2001) 1103-1119.

[22] A. Abedini, D.P. Raleigh, A critical assessment of the role of helical intermediates in amyloid formation by natively unfolded proteins and polypeptides, Protein Eng. Des. Sel. 22 (2009) 453-459.

[23] K. Matsuzaki, T. Okada, M. Tsukuda, K. Ikeda, Y. Sohma, Y. Chiyomori, A. Taniguchi, S. Nakamura, N. Ito, Y. Hayashi, Y. Kiso, Design, synthesis, and biophysica properties of a helical abeta 1-42 analog: inhibition of fibrillogenesis and cytotoxicity, Biochem. Biophys. Res. Commun. 371 (2008) 777-780.

[24] B. Vestergaard, M. Groenning, M. Roessle, J.S. Kastrup, M. van de Weert, J.M. Flink, S. Frokjaer, M. Gajhede, D.I. Svergun, A helical structural nucleus is the primary elongating unit of insulin amyloid fibrils, PLoS Biol. 5 (2007) 1089-1097.
[25] A. Olofsson, T. Borowik, G. Groebner, A.E. Sauer-Eriksson, Negatively charged phospholipid membranes induce amyloid formation of medin via an alpha-helical intermediate, J. Mol. Biol. 374 (2007) 186-194.

[26] G. Brezesinski, E. Maltseva, H. Moehwald, Adsorption of amyloid beta (1-40) peptide at liquid interfaces, Z. Phys. Chem. (Muenchen, Ger.) 221 (2007) 95-111.

[27] K. Pagel, T. Vagt, B. Koksch, Directing the secondary structure of polypeptides at will: from helices to amyloids and back again? Org. Biomol. Chem. 21 (2005) 3843-3850.

[28] K. Pagel, T. Seri, H. von Berlepsch, J. Griebel, R. Kirmse, C. Böttcher, B. Koksch, How metal ions affect amyloid formation: $\mathrm{Cu} 2+-$ and $\mathrm{zn} 2+$-sensitive peptides, Chembiochem 9 (2008) 531-636.

[29] C.J. Maynard, A.I. Bush, C.L. Masters, R. Cappai, Q.-X. Li, Metals and amyloid-beta in alzheimer's disease, Int. J. Exp. Pathol. 86 (2005) 147-159.

[30] C.C. Curtain, F.E. Ali, D.G. Smith, A.I. Bush, C.L. Masters, K.J. Barnham, Metal ions, $\mathrm{ph}$, and cholesterol regulate the interactions of alzheimer's disease amyloid-beta peptide with membrane lipid, J. Biol. Chem. 278 (2003) 2977-2982.

[31] C. Talmard, L. Guilloreau, Y. Coppel, H. Mazarguil, P. Faller, Amyloid-beta peptide forms monomeric complexes with cuii and znii prior to aggregation, ChemBioChem 8 (2007) 163-165.

[32] V. Tougu, A. Karafin, P. Palumaa, Binding of zinc(ii) and copper(ii) to the fulllength alzheimer's amyloid-beta peptide, J. Neurochem. 104 (2008) 1249-1259.

[33] V. Minicozzi, S. Morante, G.C. Rossi, F. Stellato, N. Christian, K. Jansen, The role of metals in amyloid aggregation - experiments and ab initio simulations, Int. J. Quantum Chem 108 (2008) 1992-2015.

[34] Y. Mekmouche, Y. Coppel, K. Hochgrafe, L. Guilloreau, C. Talmard, H. Mazarguil, P. Faller, Characterization of the znii binding to the peptide amyloid-beta 1-16 linked to alzheimer's disease, ChemBioChem 6 (2005) 1663-1671.

[35] C. Talmard, A. Bouzan, P. Faller, Zinc binding to amyloid-beta: isothermal titration calorimetry and zn competition experiments with zn sensors, Biochemistry 46 (2007) 13658-13666.

[36] C.D. Syme, R.C. Nadal, S.E.J. Rigby, J.H. Viles, Copper binding to the amyloid-beta (abeta ) peptide associated with alzheimer's disease: folding, coordination geometry, ph dependence, stoichiometry, and affinity of abeta-(1-28): insights from a range of complementary spectroscopic techniques, J. Biol. Chem. 279 (2004) 18169-18177.

[37] L Guilloreau, L. Damian, Y. Coppel, H. Mazarguil, M. Winterhalter, P. Faller, Structural and thermodynamical properties of cu(ii) amyloid-beta 16/28 complexes associated with alzheimer's disease, JBIC, J. Biol. Inorg. Chem. 11 (2006) 1024-1038.

[38] S. Jun, S. Saxena, The aggregated state of amyloid-beta peptide in vitro depends on Cu2 + ion concentration, Angew. Chem., Int. Ed. 46 (2007) 3959-3961.

[39] V. Pradines, A.J. Stroia, P. Faller, Amyloid fibrils: modulation of formation and structure by copper(ii), New J. Chem. 32 (2008) 1189-1194.

[40] A.I. Bush, W.H. Pettingell, G. Multhaup, M.D. Paradis, J.-P. Vonsattel, J.F. Gusella, K. Beyreuther, C.L. Masters, R.E. Tanzi, Rapid induction of alzheimer abeta amyloid formation by zinc, Science (Washington, D. C.) 265 (1994) 1464-1467.

[41] A.I. Bush, C.L. Masters, R.E. Tanzi, Copper, beta -amyloid, and alzheimer's disease: tapping a sensitive connection, Proc. Natl. Acad. Sci. U. S. A. 100 (2003) 11193-11194.

[42] L. Guilloreau, S. Combalbert, A. Sournia-Saquet, H. Mazarguil, P. Faller, Redox chemistry of copper-amyloid-beta : the generation of hydroxyl radical in the presence of ascorbate is linked to redox-potentials and aggregation state, ChemBioChem 8 (2007) 1317-1325.

[43] J. Zou, K. Kajita, N. Sugimoto, Cu2 + inhibits the aggregation of amyloid betapeptide (1-42) in vitro, Angew. Chem., Int. Ed. 40 (2001) 2274-2277.

[44] T. Kowalik-Jankowska, M. Ruta-Dolejsz, K. Wisniewska, L. Lankiewicz, H. Kozlowski, Copper(ii) complexation by human and mouse fragments (11-16) of beta-amyloid peptide, Dalton (2000) 4511-4519.

[45] C. Harford, B. Sarkar, Amino terminal cu(ii)- and ni(ii)-binding motif of proteins and peptides: metal binding, dna cleavage, and other properties, Acc. Chem. Res. 30 (1997) 123-130.

[46] V.V. Andrushchenko, H.J. Vogel, E.J. Prenner, Optimization of the hydrochloric acid concentration used for trifluoroacetate removal from synthetic peptides, J. Pept. Sci. 13 (2007) 37-43.

[47] C.R. Flach, A Gericke, R. Mendelsohn, Quantitative determination of molecular chain tilt angles in monolayer films at the air/water interface: Infrared reflection/ absorption spectroscopy of behenic acid methyl ester, J. Phys. Chem. B 101 (1997) 58-65.

[48] M. Schiewek, M. Krumova, G. Hempel, A. Blume, Pressure jump relaxation setup with ir detection and millisecond time resolution, Rev. Sci. Instrum. 78 (2007) 045101/1-045101/6.

[49] J.S. Pedersen, I.W. Hamley, Analysis of neutron and x-ray reflectivity data by constrained least-squares methods, Physica B (Amsterdam) 198 (1994) 16-23.

[50] J.S. Pedersen, I.W. Hamley, Analysis of neutron and x-ray reflectivity data. ii. constrained least-squares methods, J. Appl. Crystallogr. 27 (1994) 36-49.

[51] J.M. Mason, K.M. Arndt, Coiled coil domains: stability, specificity, and biological implications, Chembiochem 5 (2) (2004) 170-176.

[52] O.D. Monera, C.M. Kay, R.S. Hodges, Electrostatic interactions control the parallel and antiparallel orientation of alpha-helical chains in two-stranded alpha-helical coiled-coils, Biochemistry 33 (1994) 3862-3871.

[53] P. Burkhard, S. Ivaninskii, A. Lustig, Improving coiled-coil stability by optimizing ionic interactions, J. Mol. Biol. 318 (3) (2002) 901-910.

[54] D.W. Urry, Protein conformation in biomembranes. Optical rotation and absorption of membrane suspensions, Biochim. Biophys. Acta, Rev. Biomembr. 265 (1972) 115-168.

[55] L.K. Tamm, S.A. Tatulian, Infrared spectroscopy of proteins and peptides in lipid bilayers, Q. Rev. Biophys. 30 (4) (1997) 365-429. 
[56] D. Dieudonne, A. Gericke, C.R. Flach, X. Jiang, R.S. Farid, R. Mendelsohn, Propensity for helix formation in the hydrophobic peptides $\mathrm{k} 2(\mathrm{la}) x(x=6,8,10,12)$ in monolayer, bulk, and lipid-containing phases. Infrared and circular dichroism studies, J. Am. Chem. Soc. 120 (1998) 792-799.

[57] H. Lavoie, B. Desbat, D. Vaknin, C. Salesse, Structure of rhodopsin in monolayers at the air-water interface: a pm-irras and x-ray reflectivity study, Biochemistry 41 (2002) 13424-13434

[58] A.H. Martin, M.B.J. Meinders, M.A. Bos, M.A. Cohen Stuart, T. van Vliet, Conformational aspects of proteins at the air/water interface studied by infrared reflection-absorption spectroscopy, Langmuir 19 (2003) 2922-2928.

[59] M. Dyck, A. Kerth, A. Blume, M. Loesche, Interaction of the neurotransmitter, neuropeptide $y$, with phospholipid membranes: infrared spectroscopic characterization at the air/water interface, J. Phys. Chem. B 110 (2006) 22152-22159.

[60] L. Wang, J.W. Brauner, G. Mao, E. Crouch, B. Seaton, J. Head, K. Smith, C.R. Flach, R. Mendelsohn, Interaction of recombinant surfactant protein d with lipopolysac- charide: conformation and orientation of bound protein by irras and simulations, Biochemistry 47 (2008) 8103-8113.

[61] A.H. Muenter, J. Hentschel, H.G. Boerner, G. Brezesinski, Characterization of peptide-guided polymer assembly at the air/water interface, Langmuir 24 (2008) 3306-3316.

[62] M. Lepere, C. Chevallard, G. Brezesinski, M. Goldmann, P. Guenoun, Crystalline amyloid structures at interfaces, Angew. Chem., Int. Ed. 48 (2009) 5005-5009.

[63] J. Daillant, M. Alba, High-resolution X-ray scattering measurements: I. surfaces, Rep. Prog. Phys. 63 (2000) 1725-1777.

[64] M.A. Wells, C. Jelinska, L.L.P. Hosszu, C.J. Craven, A.R. Clarke, J. Collinge, J.P. Waltho, G.S. Jackson, Multiple forms of copper (ii) co-ordination occur throughout the disordered n-terminal region of the prion protein at ph 7.4, Biochem. J. 400 (2006) 501-510. 